\title{
ENTRE CORRESPONDÊNCIAS E REPRESENTAÇÕES: A CONSTITUIÇÃO DA BIBLIOTECONOMIA MODERNISTA NO BRASIL
}

\author{
BETWEEN LETTERS AND REPRESENTATIONS: \\ THE MAKING OF MODERN LIBRARIANSHIP IN BRAZIL
}

\section{Silvana Arduini \\ Edmir Perrotti}

Resumo: O texto aqui apresentado visa delinear o percurso a ser desenvolvido como projeto de doutorado em Ciência da Informação- na ECA/USP. Refere-se a um estudo das relações entre Biblioteca e Educação, no período entre 1930 e 1959, na cidade de São Paulo, a partir de levantamento e análise de documentos da época, envolvendo remanescentes do Modernismo, especialmente Rubens Borba de Moraes, diretamente vinculado ao campo das bibliotecas e da biblioteconomia. Pretende-se averiguar as concepções de biblioteca e de biblioteconoma em causa, os caminhos e descaminhos das propostas então objetivadas e inscritas no projeto de criação do Departamento de Cultura, por Mário de Andrade, na cidade de São Paulo e a adequação ou não das propostas aos processos histórico-culturais que ganharam folego na Era Vargas e nos períodos que o sucederam. O trabalho é guiado pela seguinte hipótese: os modernistas concebiam a biblioteca numa perspectiva educativa que ultrapassava sua função de instituição de conservação cultural. Por outro lado, tal perspectiva não conseguiu se consolidar e expandir, no processo de crescimento da cidade, especialmente nos anos 50 e 60 . A "era da informação", suas novas dinâmicas e exigências, teria reduzido essa dimensão formativa, substituindo o paradigma educacional pelo informacional, produzindo fratura responsável pelo apagamento da memória cultural e da importância da biblioteca e da biblioteconomia como instituições de educação e de cultura. Trata-se de uma pesquisa qualitativa, realizada a partir de séries documentais sob guarda do Instituto de Estudos Brasileiros (IEB) e também do Centro de Pesquisa e Documentação de História Contemporânea do Brasil (CPDOC), além de fundos dispersos em diferentes arquivos. A pesquisa contribuirá para resgatar aspectos fundamentais da biblioteca e da biblioteconomia no país, bem como para fornecer elementos teóricos e metodológicos para se dimensionar o lugar da biblioteca nas chamadas "culturas da informação", no Brasil e fora do Brasil.

Palavras-chave: Biblioteconomia, Democratização cultural, Educação, História da cidade de São Paulo, Infoeducação.

Abstract: The project aims to build a historical cultural analysis on the relationship between Library and Education, between 1930 and 1959 in the city of São Paulo. From the analysis of documents of the time, we seek to determine if the discontinuity of the projects developed in that period would be related to the non-adaptation of that model to the process of urbanisation that gained weight after the industrialisation of São Paulo. The question that served as hypothesis for the elaboration of the project was: Would this phenomenon have caused the reduction of the library to the informational function? This is a qualitative research, based on documentary series under the custody of the Institute of Brazilian Studies (IEB) and also the Centre for Research and Documentation of Contemporary History of Brazil (CPDOC), as well as funds dispersed in different archives. This research will contribute to recover fundamental aspects of library and librarianship in the country, and also to contribute 
VI Seminário de Pesquisa em Ciência da Informação do PPGCI 2017

Escola de Comunicações e Artes - Universidade de São Paulo

theoretically and methodologically to discuss the place of library in the "information cultures", inside and outside Brazil.

Keywords: Cultural Democratization, Education, History of city of São Paulo, Information Education, Librarianship.

\section{Introdução}

Ao tentar compreender a intensa onda de importações de modelos de biblioteca e de educação para informação, percebemos na esparsa literatura a respeito ${ }^{1}$ uma lacuna, de onde se deduz haver espaço para desenvolver novos estudos sobre a relação entre Biblioteca e Educação. Longe de querer encontrar no passado explicações deterministas, o projeto aqui resumido busca na história de um campo $^{2}$, pistas que possam formar um corpus de representações acerca das concepções da relação Biblioteca e Educação. Propõe-se a partir deste estudo contribuir para o resgate do processo de constituição da(s) Biblioteconomia(s) ${ }^{3}$ brasileiras, especialmente no que tange aos aspectos culturais e sociais do campo.

Como recorte espaço-temporal, optou-se por privilegiar as ações desenvolvidas pelo Departamento de Cultura e Recreação e também pelo Ministério da Educação e Saúde, a partir da década de trinta até o final da década de cinquenta. O recorte temporal justifica-se pelo fato de que tais anos foram cruciais para o desenvolvimento da Biblioteconomia na cidade de São Paulo e no país, pois foi nesse período, efetivou-se a criação da Divisão de Bibliotecas (1936) no Departamento de Cultura de São Paulo; também, a primeira Escola de Biblioteconomia do Brasil (1936); a primeira biblioteca infantil do Brasil - por Cecília Meireles (1932); a primeira biblioteca infantil de São Paulo - por Lenyra Fraccarolli e Monteiro Lobato (1936) e ainda o Instituto Nacional do Livro, em âmbito federal (1937), dentre outras iniciativas. O recorte geográfico apoia-se no fato de que boa parte das ações e processos ligados à institucionalização da biblioteconomia tiveram início na cidade de São

${ }^{1}$ Ao revisitarmos a literatura, vimos que diferentes aspectos da relação entre Biblioteca e Educação são estudados por variadas disciplinas do conhecimento, mas que, muitas vezes, estas não dialogam entre si. Por exemplo, ao pesquisar sobre bibliotecas (escolares, públicas, comunitárias e especializadas) teremos acesso a uma produção majoritariamente oriunda da Biblioteconomia; entretanto, o livro tem sido objeto com mais frequência da história e da editoração. No que concerne à leitura, averiguamos maior interesse dos educadores sobre aspectos relacionados às funções do livro; ademais, a biblioteca é vista, muitas vezes, como anexo da sala- de-aula.

${ }^{2}$ Aqui entendido como espaço de relações sociais, intelectuais e culturais que não é neutro. Ao contrário, é definido por interesses e conflitos de diferentes ordens (BOURDIEU, 2002). Compreende um conjunto de institucionalizações que vão desde a formação de comunidades de pares até a produção intelectual e ou artística.

${ }^{3}$ Antonio Agenor Briquet de Lemos em texto apresentado no fórum de Formação do Profissional da Informação de 2014 na ECA/USP e publicado posteriormente na Revista de Ciência da Informação e Documentação, discorre sobre as diferentes facetas da biblioteconomia ao longo da história. Ver: Lemos, 2014.

Revista Brasileira de Biblioteconomia e Documentação, São Paulo, v. 13, n. esp., p. 35-40, set. 2017. 
VI Seminário de Pesquisa em Ciência da Informação do PPGCI 2017

Escola de Comunicações e Artes - Universidade de São Paulo

Paulo, em especial por pessoas que atuaram no Departamento de Cultura de São Paulo. Além do mais, projetos mobilizados no Ministério da Educação, como, por exemplo, o Instituto Nacional do Livro, tiveram circulação e interferências diretas em políticas públicas de biblioteca, livro e educação.

\section{Objetivo}

Como objetivo geral da pesquisa definimos construir uma análise histórico cultural da relação entre Biblioteca, Biblioteconomia e Educação, no período de 1930 a 1959, na cidade de São Paulo, e a partir das pistas levantadas compreender como tal construção, situada local e temporalmente, poderá ajudar a entender o processo de institucionalização da "Biblioteconomia Educativa", no Brasil. Dentre os objetivos específicos visamos: 1) Investigar as articulações conceituais sobre Biblioteca e Educação mobilizadas na atuação do Departamento de Cultura e do Ministério da Educação, quando da criação do INL, no que tange aos projetos de biblioteca, leitura e livro; 2) Descrever o processo de institucionalização da relação Biblioteca e Educação no período estudado; 3) Sistematizar as concepções de biblioteca mobilizadas no processo de consolidação de projetos como a Divisão de Bibliotecas e o Instituto Nacional do Livro; com vistas a levantar seus limites, confluências e propulsões para a época; 4) Analisar a circulação de conceitos e experiências de biblioteca no período, bem como sua influência para a institucionalização da(s) biblioteconomia(s) e da profissão de bibliotecário estabelecida(s) no Brasil, no período.

\section{Metodologia}

A fim de cumprir os objetivos propostos, estabelecemos três etapas principais. A primeira será o levantamento de documentos (oficiais/profissionais, pessoais e jornalísticos); a segunda versa sobre a seleção e análise descritiva do corpus; a terceira consiste em construir uma análise da representação triangular da relação entre Biblioteca e Educação no período.

Como espaço privilegiado para o levantamento do corpus documental a ser estudado temos o Instituto de Estudos Brasileiros (IEB), o Centro de Pesquisa e História Contemporânea do Brasil (Cpdoc) da Fundação Getúlio Vargas, os acervos da Biblioteca Brasiliana Guita e José Mindlin, o Arquivo da Escola Caetano de Campos, o Arquivo da Biblioteca Monteiro Lobato de São Paulo, o Centro Histórico do Mackenzie, o Centro de Documentação da Fundação Escola de Sociologia e Política, a Hemeroteca Digital da

\footnotetext{
${ }^{4}$ Partimos do pressuposto da existência de distinções, no interior da "biblioteconomias". Assim, em função dos objetivos buscados, teríamos a "biblioteconomia conservação", a "biblioteconomiadocumentação ou documentária" e a "biblioteconomia educativa".
}

Revista Brasileira de Biblioteconomia e Documentação, São Paulo, v. 13, n. esp., p. 35-40, set. 2017. 
VI Seminário de Pesquisa em Ciência da Informação do PPGCI 2017

Escola de Comunicações e Artes - Universidade de São Paulo

Biblioteca Nacional, a Hemeroteca da Biblioteca Mário de Andrade de São Paulo e o Arquivo Municipal de São Paulo.

Serão analisados documentos de natureza oficial/profissional, pessoal e jornalística produzidos e/ou publicados no período entre 1930 e 1959 pelo Departamento de Cultura de São Paulo, pelo Instituto Nacional do Livro e pelos principais atores do processo de institucionalização da Biblioteconomia em São Paulo (Rubens Borba de Moraes, Adelpha de Figueiredo, Lenyra Fraccaroli e Edson Nery da Fonseca). Dentre as tipologias documentais que iremos analisar estão: escritas epistolares, relatórios, projetos políticos, publicações em diários oficiais; fotografias, cartões postais, cartazes, desenhos, rascunhos e artigos de jornal sobre biblioteca, biblioteconomia e políticas de leitura.

\section{Relação entre Biblioteca e Educação: caracterização}

Ao longo da história brasileira, é possível identificar e comparar diferentes concepções de biblioteca. Entretanto, definições enciclopédicas, que abordam a biblioteca apenas como local de reunião de coleções de livros para disponibilização do acervo ao público interessado (BIBLIOTECA, 2008), não circunscrevem a gama simbólica que envolve as relações entre sujeitos e saberes. No entendimento de Jacob (2008), biblioteca é ao mesmo tempo espaço de continuidade e também de ruptura com a tradição, ou seja, lugar de memória, espaço produtor de esquecimento. Em consonância com tais aspectos, Perrotti; Pieruccini (2016) defendem que a noção de biblioteca pode ser compreendida a partir de três paradigmas: o da conservação, o da difusão e o da apropriação cultural. O primeiro deles se refere ao paradigma da conservação. Como num templum, esse tipo de biblioteca ocupa-se da guarda do conhecimento como memória social ${ }^{5}$, nesse caso, a constituição do acervo e sua disponibilização dependem das políticas patrimoniais da instituição que regula a biblioteca. Um outro paradigma é o da biblioteca emporium. Bastante vigente em nosso tempo, esse tipo de biblioteca tem surgido como forma de negar a ênfase na preservação do patrimônio e adotar um modelo "moderno", 'de difusão", de biblioteca. Recorre a estratégias de gestão, em especial de marketing, para atrair novos clientes ${ }^{6}$. O terceiro paradigma enfatiza a biblioteca como espaço de relações sociais, simbólicas e materiais. Como num forum, sujeitos com diferentes repertórios culturais ${ }^{7}$ são acolhidos como protagonistas na constituição do projeto de biblioteca, e também permitem formar-se a partir das relações ali estabelecidas (PERROTTI; PIERUCCINI, 2016). Trata-se de um dispositivo dialógico (PIERUCCINI,

\footnotetext{
${ }^{5}$ Ver Nora (1993).

${ }^{6}$ Assim são chamados os sujeitos que frequentam a biblioteca.

${ }^{7}$ Ver a noção de habitus em diversas obras de Bourdieu, como por exemplo, Bourdieu (1992).

Revista Brasileira de Biblioteconomia e Documentação, São Paulo, v. 13, n. esp., p. 35-40, set. 2017.
} 
VI Seminário de Pesquisa em Ciência da Informação do PPGCI 2017

Escola de Comunicações e Artes - Universidade de São Paulo

2004) cujo processo de construção de relações com o universo simbólico e material orienta os projetos dessas bibliotecas. Para Parrochia (2001), a biblioteca é um organismo vivo que não se contenta em conservar a memória, ela também produz conhecimento. O filósofo apresenta a biblioteca como um repositório o qual, como um reservatório de água, conserva, mas também sabe deixar "fluir" o que estava armazenado de forma a abrir espaço para o novo pelos sujeitos que dialogam, interagem, nadam nas “águas” do reservatório.

\section{Considerações finais}

Por ser este um projeto de pesquisa em andamento, pretendemos ao final da investigação poder lançar luzes consistentes sobre a institucionalização da biblioteconomia educativa brasileira, respondendo a questões como: em que momento a biblioteca começou a ser entendida como instância educativa? Como isso se iniciou, com que objetivos, como evoluiu, como modificou-se? Além do mais, pretendemos, também, contribuir com o repertório de indagações que fazemos hoje sobre as concepções de cultura e conhecimento inseridas no processo de redefinição da biblioteca e do lugar da biblioteconomia, na contemporaneidade, quando o imperativo da informação ganhou o espaço social, colocando em questão nossas relações com a memória, o conhecimento e a cultura.

Cabe ressaltar que a compreensão dos paradigmas vigentes no presente obriga-nos a revisitar o passado. Se a visão e o mergulho nos fatos presentes são essenciais, não são, no entanto, suficientes para explicar relações específicas de um contexto dado e especialmente complexo, como é o caso da biblioteca, da biblioteconomia, da informação, da cultura e da educação na sociedade brsileira.

\section{Referências}

BIBLIOTECA. In: FARIA, Maria Isabel. PERICÃO, Maria da Graça. Dicionário do livro: da escrita ao livro eletrônico. São Paulo, EdUSP, 2008.

BOURDIEU, Pierre. Campo de poder, campo intelectual. Buenos Aires: Montressor Jungla Simbólica, 2002.

BOURDIEU, Pierre. As regras da arte: gênese e estrutura do campo literário. Sao Paulo: Companhia das Letras, 2005.

LEMOS, Antonio Agenor Briquet de. Em busca dos temas perdidos. InCID: R. Ci. Inf. e Doc., Ribeirão Preto, v. 5, n. 2, p. 34-50, set. 2014/fev. 2015.

NORA, Pierre. Entre história e memória: a problemática dos lugares. Revista Projeto

História, São Paulo, v. 10, p. 7-28, 1993. 
VI Seminário de Pesquisa em Ciência da Informação do PPGCI 2017

Escola de Comunicações e Artes - Universidade de São Paulo

PARROCHIA, D. Nécessité des réservoirs et exigence des flux : vers une néo-

bibliothéconomie. BBF, v. 46, n. 1, p. 38-46, 2001.

PERROTTI, Edmir; PIERUCCINI, Ivete. Infoéducation: ceci n'est pas une pipe À la recherche d'une troisième rive. Mediadoc Apden, n. 16, jun 2016, p. 18-21.

PIERUCCINI, I. A ordem informacional dialógica: estudo sobre a busca de informação em Educação. 2004. 194 f. Tese (Doutorado) - Escola de Comunicações e Artes, Universidade de São Paulo, São Paulo. Disponível em:<

http://www.teses.usp.br/teses/disponiveis/27/27143/tde-14032005-144512/pt-br.php>. Acesso em: jun. de 2015.

\section{Sobre a autora e o autor}

\section{Silvana Arduini}

Doutoranda em Ciência da Informação pela Escola de Comunicações e Artes, da Universidade de São Paulo.

Membro do COLABORi - Colaboratório de Infoeducação da ECA/USP

silmitcamp@yahoo.com.br

\section{Edmir Perrotti}

Professor Sênior do Departamento de Informação e Cultura da Escola de Comunicações e Artes, da Universidade de São Paulo. Criador e diretor científico do COLABORi Colaboratório de Infoeducação da ECA/USP

perrotti@usp.br 